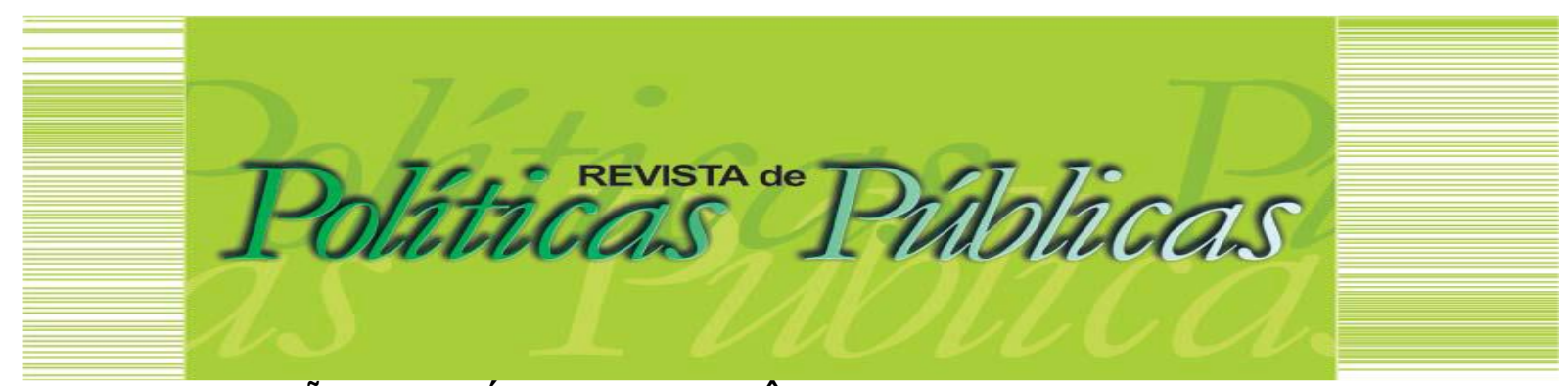

\title{
A PARTICIPAÇÃO NA POLÍTICA DE ASSISTÊNCIA SOCIAL: debates a partir da literatura de eventos científicosi
}

\author{
Paula Raquel da Silva Jales ${ }^{1}$ \\ Solange Maria Teixeira ${ }^{2}$
}

\section{Resumo}

Numa conjuntura marcada pela desqualificação e desfinanciamento das Políticas Públicas, em especial a de Assistência Social, deregressões dos direitos sociais, bem como pela perseguição ao pensamento crítico, progressista e de esquerda, faz-se extremamente importante discutir a participação.Este artigo, fruto de tese de doutorado, objetiva apresentar os resultados da pesquisa bibliográfica em 58 artigos publicados em três eventos científicos internacionais sobre a participação na Política de Assistência Social em disputa nos projetos político-ideológicos e a filiação dos autores ou defesa desses projetos. Trata-se de uma revisão integrativa de literatura de eventos científicos sobre Políticas Públicas. Evidenciou-se que a produção científica é contra-hegemônica ao projeto burguês, particularmente ao neoliberalismo, apesar das contradições discursivas indicadas em alguns trabalhos.

Palavras-chave: Participação. Política de Assistência Social. Eventos científicos.

\section{PARTICIPATION IN SOCIAL ASSISTANCE POLICY: debates from the literature of scientific events}

\begin{abstract}
In an environment marked by the disqualification and de-financing of Public Policies, especially that of Social Assistance, regressions of social rights, as well as the pursuit of critical, progressive and left-wing thinking, it is extremely important to discuss participation. This article, the result of a doctoral thesis, aims to present the results of the bibliographic research in 58 articles published in three international scientific events on the participation in the Social Assistance Policy in dispute in the political-ideological projects and the affiliation of the authors or defense of these projects. This is integrative review of the literature on scientific events on public policies. It became evident that scientific production is counter-hegemonic to the bourgeois project, particularly to neoliberalism, despite the discursive contradictions indicated in some works.
\end{abstract}

Keywords: Participation. Social Assistance Policy. Scientific events

Artigo recebido em: 23/09/2020 Aprovado em: 20/05/2021

DOI: http://dx.doi.org/10.18764/2178-2865.v25n1p334-353

\footnotetext{
1 Assistente Social. Doutora em Políticas Públicas pela Universidade Federal do Piauí (UFPI). Membro do Núcleo de Pesquisa sobre Estado e Políticas Públicas da UFPI, do grupo de pesquisa GEP Margens da UECE e do grupo Políticas de Seguridade Social, Movimentos Sociais e Trabalho do Serviço Social vinculado ao Laboratório de Seguridade Social e Serviço Social da UECE. E-mail: paularaquel.12@gmail.com

2 Assistente Social. Doutora em Políticas Públicas pela Universidade Federal do Maranhão (UFMA). Professora e pesquisadora da Universidade Federal do Piauí (UFPI) junto aos Cursos de Graduação em Serviço Social e à PósGraduação em Políticas Públicas, em nível de Doutorado e Mestrado. E-mail: solangemteixeira@hotmail.com.
} 


\section{INTRODUÇÃO}

O presente artigo é fruto de tese de doutorado elaborada no Programa de Políticas Públicas da Universidade Federal do Piauí (UFPI). Ele apresenta os resultados da pesquisa bibliográfica realizada nos anais de três eventos internacionais de Políticas Públicas Sociais no Brasil com o intuito de evidenciar as principais tendências na produção científica em relação à participação na Política de Assistência Social. Além disso, indica as áreas do conhecimento que têm se dedicado a essa discussão, os principais temas/assuntos tratados nos textos e a metodologia adotada. Objetivouse perceber se os autores e seus artigos têm contribuído na direção da afirmação do projeto políticoideológico ${ }^{1}$ hegemônico ou em sua problematização, compreensão crítica de suas contradições e abertura para o fortalecimento de projetos contra-hegemônicos no sentido da construção de outra sociabilidade.

Várias são as pesquisas que procuram entender e explicar as contradições de exercício do controle social na Assistência Social sob o contexto da relação entre poder público, trabalhadores, entidades socioassistenciais e usuários, logo, do sentido político de participação, próximo do projeto democrático constitucional que é a participação cidadã. Identificou-se, porém, uma lacuna de estudos a respeito de outros sentidos dados à participação, especialmente aquele recente em que se relacionaa parceria estabelecida entre governos e entidades socioassistenciais para a execução de serviços, programas e projetos da Política de Assistência Social, com nítida transferência de responsabilidade para a sociedade, perspectiva e sentido que avança na legislação do Sistema Único de Assistência Social (SUAS), bem como outros sentidos e suas filiações político-ideológicas. Embora as pesquisas de renomadas intelectuais² evidenciem a existência de perspectivas diferentes na condução e na execução da Política Nacional de Assistência Social (PNAS) e do SUAS, o caráter inédito da tese foi entender por que e como a participação é disputada por projetos político-ideológicos, no bojo da Política Pública social em pauta, e os sentidos ambíguos que ela assume, resultante desses projetos em tensão e suas interpenetrações, por isso a opção pela categoria participação.

Esse debate é de extrema relevância em uma conjuntura marcada pela deslegitimação de pactos que criaram direitos sociais, desfinanciamento e precarização das Políticas Públicas de cariz social que garantiam aqueles direitos, bem como pelo crescimento da Nova Direita e sua perseguição ao pensamento crítico, progressista e de esquerda rotulado nos atuais discursos de representantes do governo federal como doutrinação ideológica, destituindo o seu caráter científico e obscurecendo as 
A PARTICIPAÇÃO NA POLÍTICA DE ASSISTÊNCIA SOCIAL: debates a partir da literatura de eventos científicos

disputas político-ideológicas que perpassam pelos três poderes no país e os campos de conhecimento científico.

Trata-se de uma pesquisa bibliográfica ou de literatura denominada de revisão integrativa, que, segundo Ercole, Melo e Alcoforado (2014, p. 9),tem como "[...] finalidade sintetizar resultados obtidos em pesquisas sobre um tema ou questão, de maneira sistemática, ordenada e abrangente", geralmente em bases de dados on-line. Conforme as autoras, "[...] é denominada integrativa porque fornece informações mais amplas sobre um assunto/problema, constituindo, assim, um corpo de conhecimento" (ERCOLE; MELO; ALCOFORADO, 2014, p. 9). Para a realização desta pesquisa, elegeram-se três eventos científicos nas áreas das políticas públicas para análise dos artigos que trabalham com a discussão da participação na Assistência Social. Os resultados da pesquisa foram organizados em dois tópicos: o primeiro detalha a forma de realização do levantamento e análise bibliográfica, seguido da apresentação de um breve perfil dos artigos;o segundo discute as tendências da participação na Política de Assistência Social na produção científica. A conclusão evidencia o direcionamento político-ideológico das publicações analisadas.

\section{PROCEDIMENTOS METODOLÓGICOS E PERFIL DOS TRABALHOS CIENTÍFICOS}

A Jornada Internacional de Políticas Públicas (JOINPP), o Encontro Internacional de Política Social e Encontro Nacional de Política Social (EIPS/ENPS) e o Simpósio Internacional sobre Estado, Sociedade e Políticas Públicas (SINESPP) foram os três eventos selecionados para a pesquisa bibliográfica. Os critérios de inclusão foram: ser evento internacional de Políticas Públicas ou Política Social promovido por programa de pós-graduação dessas mesmas áreas e com Anais online.

A JOINPP ocorre bianualmente desde 2003 sob a coordenação do Programa de PósGraduação em Políticas Públicas do Centro de Ciências Sociais (CCSO) da Universidade Federal do Maranhão (UFMA). Os Anais ficam disponíveis on-line no site do evento e os principais trabalhos científicos são publicados em edição especial da Revista de Políticas Públicas da UFMA, indexada à Scientific Electronic Library Online (SciELO) e vinculada ao referido programa de pós-graduação no ano posterior à Jornada.

O EIPS/ENPS é realizado todos os anos pelo Programa de Pós-Graduação em Política Social do Centro de Ciências Jurídicas e Econômicas (CCJE) da Universidade Federal do Espírito Santo (UFES). A primeira edição do Encontro Nacional foi em 2006, junto com o Encontro da 
Sociedade Brasileira de Economia Política. As edições seguintes aconteceram de forma exclusiva, tendo se incorporado, a partir da sétima edição, ao Encontro Internacional, com primeira edição em $2013^{3}$, por isso há um descompasso entre as edições dos dois Encontros. Os Anais são publicados anualmente em revista eletrônica indexada à SciELO.

Embora o primeiro SINESPP tenha se materializado em 2016, com periodicidade bianual alternada com a JOINPP, ele tem origem em um Simpósio Nacional realizado em 2010 pelo Programa de Pós-Graduação em Políticas Públicas do Centro de Ciências Humanas e Letras (CCHL) da Universidade Federal do Piauí (UFPI)4. Os Anais on-line são publicados em formato de livro, possuem número de International Standard Book Number (ISBN) e estão disponíveis no site do programa de pós-graduação supramencionado.

Os centros oficiais de pesquisa brasileiros classificam a área de Políticas Públicas nas Ciências Humanas, especificamente no campo da Ciência Política. Os programas de pós-graduação, contudo, ao serem criados, informam à Coordenação de Aperfeiçoamento de Pessoal de Nível Superior (CAPES) a área de concentração do curso de acordo com os objetivos, as linhas de pesquisa e o corpo docente. O Serviço Social é área de concentração dos três programas organizadores dos eventos selecionados, que atraem pesquisadores de diferentes áreas e países pela abrangência internacional.

Destaca-se que, dos 36 programas de pós-graduação reconhecidos pela CAPES na área de Serviço Social, nas 35 Instituições de Ensino Superior (IES), um terço (12) tem em sua nomenclatura as palavras "Políticas Públicas" ou "Política Social", sem levar em consideração aqueles que possuem linhas de pesquisa sobre as Políticas Públicas Sociais. Isso revela o quanto o Serviço Social se identifica e contribui para a produção na área de Políticas Públicas.

No levantamento feito nos meses de abril e maio de 2020, optou-se pela seleção de artigos das duas últimas edições de cada evento supramencionado, a saber: SINESPP, 2016 e 2018; JOINPP, 2017 e 2019; EIPS, 2018 e 2019. Os Anais abrangem, dessa forma, o período de 2016, antes do golpe político-jurídico-midiático ${ }^{6}$, e agosto de 2019 , ou seja, pesquisas realizadas durante a busca pela consolidação e o desmonte do SUAS.

Os artigos foram escolhidos pelos títulos e/ou resumos através da identificação das seguintes palavras-chave: "participação"; "controle social"; "sociedade civil"; "Assistência Social"; "entidades/instituições beneficentes, assistenciais e socioassistenciais"; "ONG"; "família"; "parceria"; e "SUAS". Num primeiro momento, selecionaram-se 91 trabalhos, sendo que oito não puderam ser lidos devido a um problema para descarregar os arquivos da plataforma da VIII JOINPP. A organização do 
A PARTICIPAÇÃO NA POLÍTICA DE ASSISTÊNCIA SOCIAL: debates a partir da literatura de eventos científicos

evento foi informada do erro, mas não teve como disponibilizar os artigos não acessados até a finalização do período de análise.

O próximo passo foi ler os 83 artigos e organizá-los por evento, modalidade de apresentação, título, formação dos autores, metodologia, eixo analítico e discussões sobre participação. Nesta fase, percebeu-se que 25 trabalhos não abordavam a participação na Política de Assistência Social, atribuindo-lhe sentidos vinculados a projetos político-ideológicos. A palavra "participação", quando utilizada em alguns textos, referia-se aos sujeitos da pesquisa de campo, à integração entre os serviços da rede socioassistencial ou à inserção dos usuários em atividades ofertadas pelo SUAS. Além disso, não discutiam nem conceituavam a participação como categoria, sendo retirados da amostra. $A$ análise concretizada nos meses de maio e junho de 2020 apreciou, portanto, 58 artigos. A tabela a seguir resume a quantidade de trabalhos lidos, incluídos e excluídos da pesquisa por edição dos três eventos.

Tabela 1 - Quantidade de artigos por edição dos eventos

\begin{tabular}{c|c|c|c}
\hline Eventos & Lidos & Incluídos & Excluídos \\
\hline VIII JOINPP & 28 & 18 & 10 \\
\hline IX JOINPP & 16 & 12 & 3 \\
\hline VI EIPS & 9 & 6 & 2 \\
\hline VII EIPS & 5 & 3 & 0 \\
\hline I SINESPP & 8 & 8 & 6 \\
\hline II SINESPP & 17 & 11 & $\mathbf{2 5}$ \\
\hline TOTAL & $\mathbf{8 3}$ & $\mathbf{5 8}$ & \\
\hline
\end{tabular}

Fonte: Elaboração própria (2020).

A maioria dos artigos foi apresentada na modalidade de comunicação oral e 12 na forma de Mesa Coordenada, sendo nove na JOINPP e três no EIPS. Ressalta-se que esse é o primeiro ano de abertura de inscrições para Mesas Coordenadas no SINESPP, não havendo essa opção nas edições anteriores. Mesmo que as comunicações orais tenham ganhado centralidade, o fato de $20 \%$ das apresentações terem sido realizadas através de Mesas Coordenadas evidencia discussões e produções no âmbito de núcleos de pesquisa sobre a participação na Política de Assistência Social.

A formação dos autores e coautores foi predominantemente em Serviço Social. Entre os primeiros, identificaram-se uma aluna de Serviço Social e um economista. Uma das assistentes sociais também era graduada em Direito e licenciada em História. Entre os segundos, havia uma aluna de Serviço Social e uma assistente social, essa última acumulava a graduação em Direito. Ressalta-se a repetição de autores que apresentaram trabalhos diferentes numa mesma ou distinta edição dos eventos pesquisados, mostrando a existência de intelectuais dedicados à produção científica sobre o assunto. Dos 58 autores, apenas três eram homens, havendo 25 coautoras mulheres. 
As pesquisas de tipo bibliográfico e documental se sobressaíram em relação às que possuíam trabalho de campo. Cinco eram fruto de trabalhos de conclusão de curso, duas de mestrado, duas de doutorado, quatro de projetos/propostas de pesquisa, dez de relatórios de pesquisa regional, uma de pesquisa nacional e duas de pesquisa internacional com Portugal. Os demais não expressaram a motivação para a realização do artigo. Duas autoras mencionaram ter o método dialético como referência para suas produções. Também foi possível identificar um estudo de caso e uma pesquisaação.

Gráfico 1 - Modalidades de pesquisa

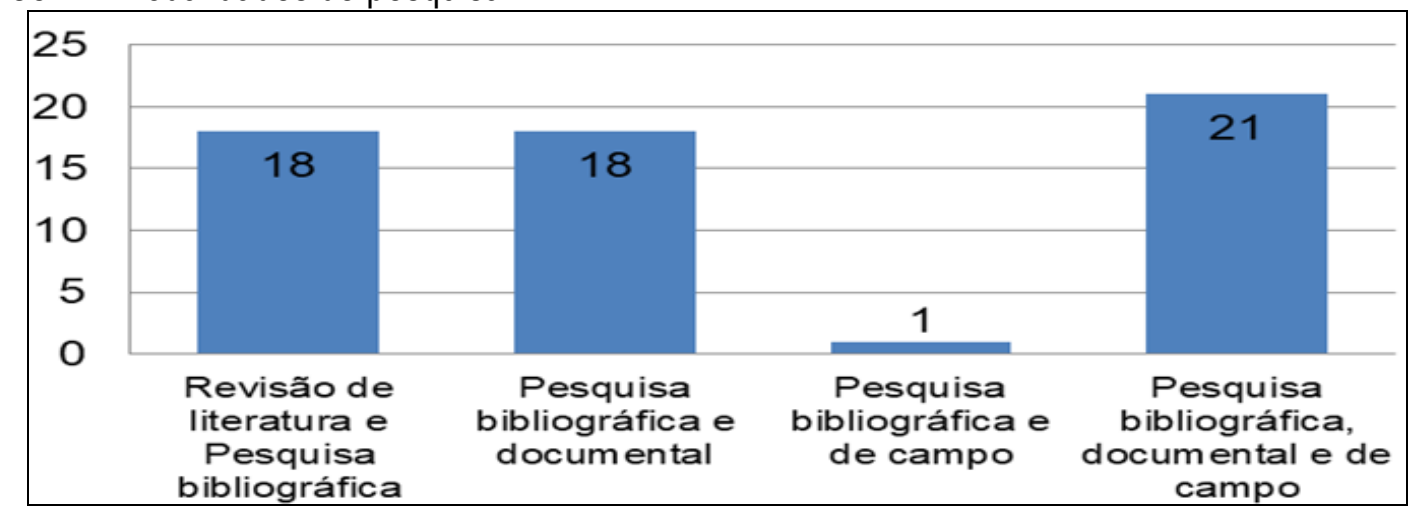

Fonte: Elaboração própria (2020).

Para finalizar este breve perfil, apresentam-se os eixos analíticos de classificação dos artigos, a saber: 1) Família e proteção social na Política de Assistência Social; 2) Implementação do SUAS; 3) Controle social no conselho; 4)Participação e mobilização na Política de Assistência Social; 5) Participação política de mulheres; 6) Cultura dominante e Assistência Social; 7) Centralidade da Política de Assistência Social na Seguridade Social; 8) Vigilância Socioassistencial; 9) Programa Criança Feliz; 10) Organizações não Governamentais (ONGs). A criação desses eixos, a partir da identificação do tema principal abordado no trabalho acadêmico, contribuiu na melhor percepção das tendências da participação na Política de Assistência Social. O Gráfico 2 apresenta a quantidade de artigos por eixo analítico.

Gráfico 2 - Eixos analíticos 
A PARTICIPAÇÃO NA POLÍTICA DE ASSISTÊNCIA SOCIAL: debates a partir da literatura de eventos científicos

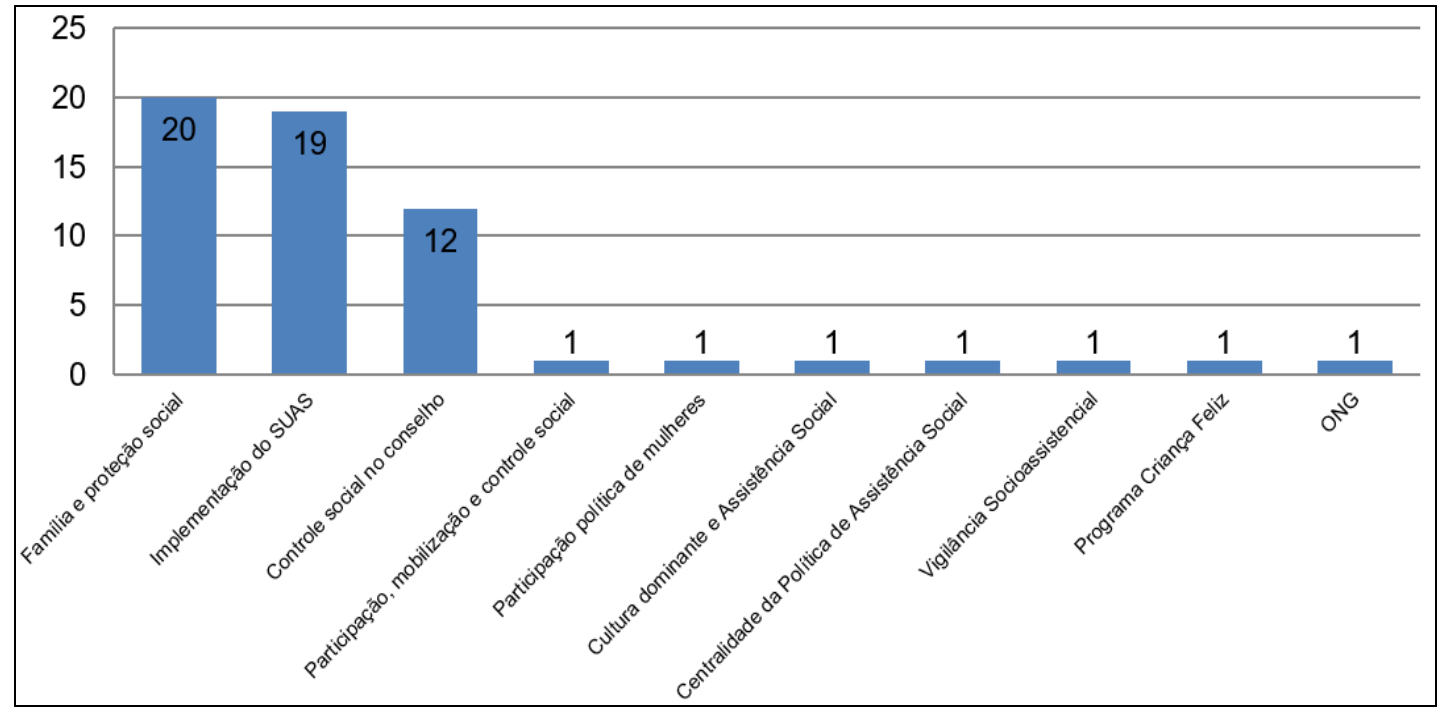

Fonte: Elaboração própria (2020).

A concentração de produções científicas nos três primeiros eixos chama a atenção para os principais sentidos da participação discutidos pelos autores e coautores dos eventos selecionados, além de evidenciar os direcionamentos político-ideológicos do texto. Isso será matéria desenvolvida no próximo tópico.

\section{DISCUSSÕES E TENDÊNCIAS DA PARTICIPAÇÃO NOS ARTIGOS ANALISADOS}

Todos os artigos apresentaram contextualização do objeto de análise na História, especialmente a partir da constituição do Estado social, e na sociedade capitalista, com destaque para o neoliberalismo,quando se abordou o cenário brasileiro, ou quando se iniciava a década de 1930, ou quando do processo de redemocratização. Foi recorrente também a referência, descrição e/ou discussão das legislações, resoluções e documentos oficiais da Política de Assistência Social. As produções foram unânimes em afirmar a Constituição Federal como um marco para o reconhecimento da Assistência como Política Pública de direito, perspectiva defendida pelas autoras que se posicionaram a respeito da temática. Apesar da percepção de que houve avanços jurídico-formais, em particular nos governos petistas (2002-2016), e o desmonte das políticas sociais, a partir de Michel Temer (2016-2018), as autoras identificaram muitas contradições na utilização de vários conceitos nos documentos legais e na forma como o SUAS vem sendo implementado nos municípios. Tudo isso mostra que prevalecem um olhar e pensamento críticos nos trabalhos acadêmicos.

No eixo "Família e proteção social na Política de Assistência Social", as autoras teceram severas críticas à tendência familista e/ou ao repasse de responsabilidades estatais às famílias, evidenciando críticas à participação de parceria solidária, no sentido de família parceira e da relação 
público-privada, embora muitas delas não utilizassem esses termos. Regina Célia Tamaso Mioto, professora do Programa de Pós-Graduação de Serviço Social da Universidade de Santa Catarina (UFSC), e Solange Maria Teixeira, professora adjunta do curso de Serviço Social da UFPI, foram as intelectuais mais citadas nessas produções a influenciarem tanto as discussões sobre as modalidades de proteção social destinadasà família como a percepção das parcerias incentivadas pelo Estado na busca de redução de suas funções protetivas orientada pela austeridade neoliberal,proteção essa que é repassada e assumida pela sociedade e pelas famílias. Um dos artigos também fez referência ao conceito de participação solidária requerida pelo Estado, a partir das análises de Laisa Regina Di Maio Campos Toledo, professora do curso de Serviço Social da Pontifícia Universidade Católica de São Paulo (PUC/SP).

As expressões da questão social, a proteção social na América Latina, a centralidade da família na Política de Assistência Social, o trabalho social com famílias, o Serviço de Proteção Integral e Atendimento à Família (PAIF), osServiços de Convivência e Fortalecimento de Vínculos (SCFV), 0 Serviço de Família Acolhedora e o Programa Bolsa Família (PBF) foram alguns dos assuntos tratados nos textos. Em quatro dos cinco artigos que investigavam o Bolsa Família houve reflexões e discussões sobre relações e desigualdades de gênero e sobre a sobrecarga da mulher no âmbito familiar, principalmente no cumprimento das condicionalidades. A possibilidade de uma autonomia financeira e de participação em espaços de construção coletiva (FARIAS; COELHO, 2017) não é suficiente para romper com o patriarcado, o machismo e a visão idealizada de "mãe-esposadoméstica".

Neste eixo há uma crítica acentuada à participação solidária, da parceria públicoprivada, da centralidade da família e dos programas de transferência de renda com condicionalidades que remetem à ampliação de encargos e contrapartidas das famílias para poderem acessar os benefícios e serviços; ao apelo às suas redes informais como forma de resolutividade da proteção social, por serem fontes de culpabilização e responsabilização das famílias pelas situações de vulnerabilidades vividas, em um contexto de retração da primazia da intervenção do Estado na oferta da proteção social via políticas sociais de ampla cobertura na condição de direitos de cidadania.

As produções sobre a implementação do SUAS discutiram os avanços, as contradições, os retrocessos e/ou a permanência do conservadorismo ou do assistencialismo na gestão, serviços, programas, projetos e benefícios socioassistenciais e no controle social. Um dos trabalhos afirma que a ruptura com a matriz político-cultural hierárquico-conservadora e autoritária ainda é um dos grandes 
A PARTICIPAÇÃO NA POLÍTICA DE ASSISTÊNCIA SOCIAL: debates a partir da literatura de eventos científicos

desafios para a efetivação da Política de Assistência Social e do sistema que a materializa (CARVALHO; BEZERRA, 2019). No geral, destacam os avanços na relação Estado versus sociedade civil que legitimam uma participação política ampliada e cidadã ao reconhecerem os usuários como sujeitos de direitos e a dimensão democrática do SUAS como espaços institucionais e não institucionais de participação de sociedade, apesar de perceberem as dificuldades, limites e entraves desse processo.

Segundo Machado (2017), a avaliação da Política de Assistência Social realizada em município de médio porte do estado do Rio de Janeiro objetivava a verificação do atendimento de metas para a continuidade de repasses dos recursos financeiros ou aplicação de sanções. Embora o Conselho Municipal de Assistência Social (CMAS) cumprisse seu papel de fiscalizador das contas, não contava com a participação dos usuários, sendo esse um dos grandes desafios do SUAS. Conforme a autora, a participação de todos os atores que compõem a política nos processos avaliativos é condição para a expansão da cidadania.

Já os resultados da pesquisa de Silva et al. (2017), um dos poucos trabalhos que discutiram o controle social e apresentaram uma definição de participação nesse eixo, revelaram que 0 Cadastro Nacional de Entidades de Assistência Social (CNEAS), em Teresina, realizado através da articulação entre a Vigilância Socioassistencial e o CMAS, contribuiu favoravelmente para a gestão pública e o reconhecimento do controle social como espaço de participação e garantia de direitos. № entanto, as autoras afirmaram que as entidades se tornaram parceiras do Estado na execução da Política de Assistência Social. Essa frase pode gerar confusão e/ou ambiguidade na forma como essa parceria vem sendo concretizada, uma vez que as autoras não conceituaram nem explicitaram o sentido atribuído à categoria, que pode ser de colaboracionismo, na mera homologação das atividades da gestão, ou de consensos obtidos nas discussões em torno da política. Mostra também a confluência perversa $^{7}$ entre o projeto neoliberal e democrático participativo.

Na compreensão de Parreira e Barcelos (2017, p. 9), que relataram o repasse de responsabilidades estatais às entidades privadas concretizado pelo Programa Comunidade Solidária e desde então o apelo à solidariedade e ao desenvolvimento de parcerias, é necessário "[...] refletir como está acontecendo cotidianamente a relação de parceria do Estado com a sociedade civil, uma vez que não deve acontecer a apropriação desta parceria [...] para implementar políticas sociais orientadas pelo modelo neoliberal". As autoras enfatizaram também a centralidade na família e em sua rede de apoio como uma forma de o Estado se destituir de sua obrigação de proteção social. Defendem a primazia estatal na condução da Política de Assistência Social. 
Outra análise que abordou as entidades socioassistenciais e os conselhos foi a de Silva (2017). O autor conclui que não houve uma laicização e estatização dessas entidades. A maioria delas é privada, perpassada por interesses corporativistas, com práticas assistencialistas e clientelistas, recebendo mais recursos estatais do que os serviços socioassistenciais. No conselho, evidenciou-se novamente a não participação dos usuários, sua sub-representação, apesar da existência de normativas para a efetiva inserção deles nesses espaços. Prevaleceu o papel consultivo dos conselhos, restritos a formalidades burocráticas. Conforme 0 autor, faz-se necessário recuperar a grande política - na concepção de Gramsci -, transformar a ordem burguesa e o Estado. Assim, a participação de parceria solidária e a gerencial são denunciadas como tendências presentes no campo da Assistência Social, mesmo no seu trânsito para a Política Pública, o que se deve ao embate entre os projetos político-ideológicos com repercussão no desenho da política e nas práticas de implementação.

Os artigos de Araújo (2019) e Both (2019a) ressaltaram alguns resultados em relação aos usuários. No primeiro, evidenciou-se a dificuldade dos usuários e dos trabalhadores de perceberem os primeiros como sujeitos, bem como a permanência de ações estigmatizantes e moralizadoras por parte dos profissionais. Destacou-se a sugestão de uma usuária para a construção de estratégias de mobilização e motivação da participação dos usuários no SUAS. De acordo com a autora, os espaços de participação podem contribuir para o enfrentamento das desigualdades e construção de uma nova concepção de cidadania, o que em tese favoreceria a participação na lógica do projeto democratizante participativo, de disputas de interesses, de lutas por hegemonia ou de contra-hegemonia das classes trabalhadoras e engrossaria as disputas pelo fundo público na satisfação das necessidades sociais.

O segundo mostrou como a lei legalizou o cidadão de direitos e os espaços de participação, no entanto realçou que essa nova identidade deve ser construída com participação da sociedade, especialmente dos usuários. A VII Conferência Nacional de Assistência Social foi, para a autora, um marco na discussão da participação e controle social no SUAS. Além disso, indicou outros espaços de participação dos usuários para além dos conselhos e conferências e destacou o papel fundamental dos equipamentos socioassistenciais no fortalecimento dessa participação. Apresentou algumas dificuldades dos trabalhadores e dos serviços na perspectiva da garantia de direitos, dentre elas o reconhecimento dos usuários como classe que vive do trabalho. Assim, os obstáculos à efetivação da participação, na perspectiva do projeto democratizante participativo, são decorrentes de uma cultura histórica da formação da sociedade brasileira, que sempre castrou a participação popular, especialmente a dos mais pobres, vistos sempre como pedintes, subalternos, subcidadãos, introjetada e reproduzida pelos próprios usuários e pelos profissionais que executam os serviços. 
A PARTICIPAÇÃO NA POLÍTICA DE ASSISTÊNCIA SOCIAL: debates a partir da literatura de eventos científicos

Quando a discussão da participação esteve articulada ao controle social, o que se chama de "participação cidadã", as pesquisas apontaram insuficiências e avanços. Dentre os elementos limitantes para a sua efetivação, destacaram-se: 1)existência do conselho como exigência formal burocrática para o cumprimento de determinações governamentais, papel homologatório, 0 que corrobora a prevalência de uma gestão gerencial; 2) indicação da presidência do conselho pelo Poder Executivo; 3) inibição da participação dos demais conselheiros pelo gestor no conselho; 4) precária infraestrutura dos espaços e capacitação dos conselheiros; 5)desconhecimento da natureza e funcionalidade do CMAS por alguns conselheiros; 6) fragilidade da participação da sociedade civil e do usuário e não participação direta deste; 7) desconhecimento de representantes no conselho por trabalhadores e usuários; 8) direito de organização, reivindicação e exercício do controle social inviabilizado pela ausência de transporte público na cidade; 9) dificuldade para a realização da conferência do ano de 2019; e 10) forte presença da matriz tradicional, cultura assistencialista, clientelista e interferência político-partidária.

Por outro lado, os avanços legais e práticos para a efetividade dessa participação foram: 1) tendência a uma gestão democrática e participativa no SUAS, com a indicação de recursos para o efetivo funcionamento dos conselhos; 2)alternância na presidência; 3) proximidade dos conselheiros com as discussões realizadas na instância de controle social; 4) representação dos usuários na maior parte dos conselhos, com destaque para a luta protagonizada pela população de rua; 5) conferências como espaços de ampla participação da população, apesar da difícil concretização das suas deliberações; e 6) incipiente reconhecimento dos usuários como sujeitos de direitos por gestores, trabalhadores e conselheiros.

Nessa perspectiva, a existência formal de mecanismos de participação cidadã no desenho da política resultante das reivindicações dos movimentos de luta reformistas/democratizantes não significa necessariamente uma conquista definitiva e inconteste, porque o desenho da política é ambíguo e contraditório, partícipe da confluência perversa com o projeto neoliberal, que, ao se apropriar desses conceitos e reformulá-los, especialmente pela falta de condições objetivas e necessárias a esses espaços, cooptação de lideranças, burocratização e formalismo, desqualifica a participação popular, ao tempo que aparenta ser democrático e de acordo com essas instâncias.

$\mathrm{Na}$ análise de Castro (2017), a implantação do SUAS é objeto de práticas políticas, espaço de disputas e conflitos entre projetos societários que têm influenciado a consolidação da cultura do direito, contrapondo-se a perspectivas conservadoras. Portanto, a contradição entre ajuda e direito é possibilidade de garantia da responsabilidade estatal com mobilização e participação dos movimentos 
sociais. A existência legal da política é um ponto importante nas lutas e decorre delas. A autora alertou também para a compreensão da relação público-privada a partir de seus paradoxos, negando interpretações de colaboração, reciprocidade. Afirmou que um conceito inovador de redes poderia contribuir para promover a participação popular. Defendeu a consolidação do SUAS e o aprofundamento das contradições na perspectiva dos direitos.

A possibilidade de construção de novas relações entre o Estado e a sociedade civil brasileira, a partir da instauração de um controle social nas Políticas Públicas, foi o enfoque do eixo "Controle social no conselho". Estado, sociedade civil, democracia, participação, espaço público, projetos políticos, controle social e/ou conselho foram categorias que integraram as discussões a fim de elucidar a relevância, as limitações e as disputas que perpassam pelas instâncias institucionais de deliberação, no sentido da defesa de uma participação consciente, crítica e legítima em direção às necessidades e interesses das classes trabalhadoras.

Como no eixo anterior, alguns trabalhos voltaram a indicar dificuldades de representação e participação dos usuários no conselho, pois, mesmo quando estiveram presentes nesses espaços, tiveram papel burocrático de comparecer às reuniões e de referendar pautas, o que reforça o sentido homologatório da participação. Três artigos evidenciaram a defesa corporativa de interesses por parte das entidades sociais ao analisarem os representantes da sociedade civil nos conselhos, sendo que um deles destacou que esse uso também era feito pelo Estado. Assim, cai por terra a tão propagada ideia do senso comum de que a sociedade civil é progressista, como se fosse homogênea, expressasse interesses populares, sendo na sua essência heterogênea, com relações diretas com os interesses de classes, das frações de classes ou dos grupos, logo muitos deles, corporativos, imediatistas e pragmáticos.

Apenas quatro produções ressaltaram a disputa entre projetos políticos, a partir de Gramsci ou de Evelina Dagnino, ao tratarem do tema do controle social e da sociedade civil. Carvalho e Silva (2017) mencionaram em seu texto a possibilidade de construção de projeto societário pelas classes subalternas, através da participação e do controle social, ou seja, como mediação para a compreensão dos seus interesses e dos antagonismos entre os interesses de classes presentes nesses espaços. Por fim, três artigos reiteraram que o projeto neoliberal transmutou a participação cidadã na relação de parceria entre o Estado e a sociedade, com repasse de responsabilidades para esta última, pela via do colaboracionismo, fortalecendo e difundindo a noção de que ofertar proteção social pela sociedade civil é a saída num contexto de redução de gasto público. 
A PARTICIPAÇÃO NA POLÍTICA DE ASSISTÊNCIA SOCIAL: debates a partir da literatura de eventos científicos

Dentre as dificuldades que atingem diretamente a materialização do controle social democrático na Política de Assistência Social e que complementam as análises precedentes, destacam-se: escolha dos representantes da sociedade civil pela sociedade política; falta de diálogo com as bases de representação; predomínio de uma participação institucionalizada; descumprimento da legislação; personalização do poder; recursos operacionais escassos; e falta de preparação técnica dos conselheiros. A participação defendida e direcionada pelo projeto político-ideológico democrático mostra-se frágil na análise feita pelos autores, posto que são alvos de ataques principalmente dos projetos neoliberal e autoritário, e não apenas um problema operacional ou político local.

Os demais artigos abordaram discussões específicas na Política de Assistência Social que não puderam ser agrupadas, por isso foram classificados e analisados individualmente. No eixo "Participação e mobilização", a pesquisa de Both (2019b) destacou várias formas de participação do usuário na Assistência Social previstas nos documentos legais (coletivo, associações, fóruns e conselhos locais de usuários; rede; e comissões ou associações comunitárias ou de moradores) e os serviços da proteção social básica, dentre eles o PAIF, como espaços que podem proporcionar a participação e mobilização dos sujeitos. Num contexto adverso às políticas sociais, acentuado pelo golpe parlamentar de 2016, identificou Frentes Nacionais de luta pela Política de Assistência Social, com a adesão de diferentes entidades e, no caso da Frente Gaúcha, com forte participação de trabalhadores, usuários e assistentes sociais. Ressaltou também a Audiência Pública sobre a Assistência Social e demais serviços infantojuvenis chamada pela Rede da Criança e do Adolescente de Porto Alegre. Defendeu o trabalho de base para potencializar as lutas e as formas de resistência.

$\mathrm{Na}$ "Participação política de mulheres", Lima (2017) analisou o discurso de mulheres que integraram um projeto social financiado pela Política de Assistência Social no município de Paracuru, no Ceará, as quais, a partir dessa iniciativa, construíram uma associação de agentes sociais. As concepções de participação política e de movimento social discutidas pela autora encontram fundamento nas compreensões de Maria da Glória Gohn. Concluiu que as mulheres se tornaram agentes políticos, imbuídas de uma nova cidadania coletiva. Entretanto, mostrou os limites dessa politização, pois, em decorrência da descontinuidade das políticas sociais, pela troca de gestões, a associação deixou de receber apoio da atual gestão municipal, por ter sido associada à gestão anterior.

A análise de Vasconcelos (2017) apresentou a trajetória histórica da Assistência Social, evidenciando a retórica discursiva da cultura dominante, por isso foi alocada no eixo de mesmo nome. Para a autora, a participação proposta no período desenvolvimentista foi falaciosa, por conceber a categoria na perspectiva de tomar parte, intervir, que só ocorreu de forma genuína com a luta dos 
movimentos sociais pela democratização nas décadas de 1970 e 1980. No contexto neoliberal, afirmou que a participação se repaginou, como se todos tivessem oportunidades iguais. $O$ Estado se retira da responsabilidade de proteção social, que é repassada à família e à sociedade, uma participação restrita e vigiada. Ressaltou que, durante a presidência de Fernando Henrique Cardoso (FHC), a participação foi estimulada com o voluntariado e as parcerias público-privadas, o que aprofundou o processo de refilantropização da Assistência Social. Defendeu o trabalho como principal direito em outra sociabilidade.

Deve-se ressaltar que as mudanças promovidas pelo governoFHC, legislando e legitimando a participação do terceiro setor na provisão de Políticas Sociais, criaram uma forma de compreender aPolítica Pública como regulada pelo Estado, mas executada também pelas organizações da sociedade civil que prestam serviços, avançando na ideia de que não se faz Política Pública sem as parcerias, sem a solidariedade, sem o voluntarismo e sem o colaboracionismo. Essa noção está presente na Política de Assistência Social, lembrando que as organizações de Assistência Social fazem parte do SUAS, estão inseridas na lógica da rede socioassistencial. Essa noção se soma à potencialização das funções protetivas da família pela política, das redes informais e formais.

Assim, em pouco tempo a participação de parceria solidária ganha terreno na política, sendo esperada, desejada e impulsionada ou potencializada, sob a retórica de que as pessoas não têm apenas problemas, mas potencialidades também, capital humano a ser desenvolvido. Trata-se, na verdade, de uma perspectiva ideológica que tem acento no novo modelo de acumulação flexível (HARVEY, 1992), que busca a colaboração produtiva dos trabalhadores, ainda que sob forte desregulamentação dos seus direitos trabalhistas e sociais, trabalhos e contratos precários, superexploração,mas também se apropria de suas iniciativas solidárias e voluntárias, de suas bandeiras de lutas,reenquadrando-as em colaboracionismo, corresponsabilizandoos trabalhadores pelas crises e principalmentepelas saídas da crise, momento em que todos devem contribuir para a retomada do desenvolvimento econômico e social, aceitar as "reformas", dentre outras medidas (MOTA, 1995).

Como destaca Abreu (2016, p. 240), "[...] as relações de parceria e negociação, aparência do atual colaboracionismo entre sujeitos antagônicos, numa flagrante tentativa de eliminar a pressão política a partir dos interesses das classes subalternas". Assim como a polarização entre interesses da burocracia estatal e a sociedade civil, como instâncias homogêneas, tende a reforçar, ainda segundo a autora, as tendências neoliberais de autonomização dessas instâncias e sua despolitização. 
A PARTICIPAÇÃO NA POLÍTICA DE ASSISTÊNCIA SOCIAL: debates a partir da literatura de eventos científicos

Nesse sentido, Braga (2018), ao discutir com autores de perspectivas teóricas diferentes sobre a centralidade da Política de Assistência Social na Seguridade Social, revelou a banalização da solidariedade; a construção de parcerias com os trabalhadores; o Programa Comunidade Solidária como transferência de responsabilidades estatais à sociedade; a fragilidade dos conselhos, especialmente em relação à participação dos usuários; e a responsabilização da família pela sua proteção social. Encontra no neoliberalismo e nos processos conservadores históricos que permanecem na Política Pública e seu sistema único como os determinantes desses novos processos e tendências. Defendeu a perspectiva dos direitos sociais afiançados pelo Estado.

A Vigilância Socioassistencial, por embasar a tomada de decisões, contribui, consoanteCarraro (2017), para o exercício do controle social e fomenta processos participativos, uma vez que a apropriação e publicização de informações e conhecimentos podem consolidar uma gestão democrática e participativa, na perspectiva dos direitos. Todavia, a autora reconheceu o contexto adverso, as contradições e os obstáculos para a materialização da Vigilância Socioassistencial, dentre eles a redução das responsabilidades do Estado, especialmente na área social, com transferência de atribuições ao setor privado, privatização das Políticas Sociais. Defendeu a formação político-cidadã e a educação permanente como formas de disputar o espaço da Política Pública e a apropriação dos dados da vigilância por todos os sujeitos que compõem o SUAS.

Há maior inteligibilidade na literatura das contradições, dos ataques e dos desmontes da política nos últimos anos. O Programa Criança Feliz foi analisado como exemplo do sucateamento das Políticas Sociais. Conforme Bezerra (2019), a apropriação do fundo público pelas classes dominantes e o processo de desmonte dos direitos da Seguridade Social ficaram mais visíveis pós-golpe de 2016. Ao repor o primeiro-damismo e fortalecer o voluntariado e o terceiro setor, o Programa aprofundou a parceria entre Estado, sociedade civil e setor privado. Nas suas palavras: "Há uma nova morfologia das políticas sociais por meio do seu sucateamento, sendo entendidas como mercadoria para valorização do capital, onde para garantir direitos 'básicos' a saída é valer-se do terceiro setor para geri-las" (BEZERRA, 2019, p. 1).

De acordo com Abreu (2016, p. 247-248), "[...] não se pode perder de vista 0 protagonismo histórico das ONGs que se mantêm como canais de denúncia, de organização e politização sobre a problemática social e de construção de possíveis alternativas na sociedade", como é o caso do ambientalismo, das discussões, denúncias e enfrentamentos da violência de gênero, raçaetnia, geracional e outras. É expressivo, todavia, consoante a autora, "[...] o papel de parte significativa dessas organizações, que tendem a crescer como interlocutoras ideais na implementação das 
estratégias privatistas do Estado neoliberal" (ABREU, 2016, p. 247), sob a retórica da ampliação da esfera pública. Nessa perspectiva, o colaboracionismo, o voluntarismo, as coparticipações e os assentimentos que engrossam a significação da participação de parceria solidária e gerencial ganham terreno na política. Mesmo que a literatura estudada seja consensual na crítica, no seu desvendamento para além da aparência imediata, reconhece sua presença e influência na Política Pública em questão, como traço histórico e contemporâneo.

$E$ finalmente 0 artigo que abordou a retração do Estado na área social e o repasse de responsabilidades estatais às ONGs: Neves e Oliveira (2018) contextualizaram o processo de dominação burguesa, o neoliberalismo, a Reforma do Estado de FHC e o incentivo ao terceiro setor. Ao discutirem sobre as instituições filantrópicas, ressaltaram o certificado de entidades beneficentes como importante para o funcionamento dessas organizações, contudo criticaram o repasse total da execução das ações sem a fiscalização do Estado e sem a publicização dos resultados positivos produzidos por instituições qualificadas. Mostraram descontentamento com a Lei $n^{0} 12.101 / 2009$, que define critérios para a classificação das entidades beneficentes de Assistência Social que prestam serviços nas áreas de Assistência Social, Saúde ou Educação. As autoras afirmaram que a legislação outorgou regras que fragilizaram a atuação, o desenvolvimento e os resultados das ONGs. Isso contraria as discussões travadas pelas pesquisadoras no referencial teórico crítico, ao sair na defesa das entidades que desenvolvem um trabalho com seriedade e culpabilizam o Estado por não fazer uma fiscalização e identificação dessas instituições.

\section{CONCLUSÃO}

A análise bibliográfica da produção em Anais identificou, portanto, a prevalência da cultura colaboracionista de cariz neoliberal na política, apresentando, em sua maioria, críticas à participação na perspectiva de parceria solidária, no sentido da relação público-privada e da família parceira, por estar na origem de processos que reduzem a responsabilidade do Estado como 0 principal ofertante de políticas e serviços sociais numa dimensão universalizante.

A literatura estudada também critica a participação gerencial, no sentido de papel homologatório dos conselhos e da participação apolítica, mostrando que essas duas perspectivas de participação, a de parceria solidária e a gerencial, aproximam-se, são colaboracionistas, legitimadoras da ordem, parte das estratégias participacionistas neoliberais, formais, tecnocráticas, 
A PARTICIPAÇÃO NA POLÍTICA DE ASSISTÊNCIA SOCIAL: debates a partir da literatura de eventos científicos

que desconsideram o saber popular e minimizam, formalizam e burocratizam os espaços democráticos de participação.

Como destaca Abreu (2016), é inerente a essa cultura participacionista neoliberal a responsabilização dos sujeitos individuais e coletivos, como a família, pela proteção social, pelo enfrentamento dos problemas sociais que sofrem, sob a denominação de protagonismo, autonomia, participação social. Trata-se de uma acomodação dentro da ordem, uma reorganização da cultura a partir da orientação neoliberal de consentimento ativo e passivo do trabalhador a essa racionalidade.

Os autores estiveram direcionados em suas pesquisas pela defesa de aspectos do projeto político-ideológico democrático participativo, como os direitos sociais, a democracia participativa, a cidadania ativa, a participação cidadã, a participação política ampliada, a mobilização social, a organização política, as resistências a toda forma de opressão às conquistas das classes dominadas, dentre outros. Isso se deve também ao fato de serem assistentes sociais e terem uma formação e atuação baseadas num projeto ético-político crítico. Nessa perspectiva, cumprem o papel de produção científica contra-hegemônica ao projeto burguês, particularmente ao neoliberalismo, apesar das contradições discursivas indicadas em dois trabalhos.

\section{REFERÊNCIAS}

ABREU, Marina Maciel. Serviço Social e a organização da cultura: perfis pedagógicos da prática profissional. 5. ed. São Paulo: Cortez, 2016.

ANAIS do Encontro Internacional de Política Social. Sobre a revista. Disponível em: http://periodicos.ufes.br/einps/about. Acesso em: 12 jun. 2020.

ARAÚJO, Cleonice Correia. Usuários(as) da Política de Assistência Social: qual o "lugar" desses sujeitos?.In: JORNADA INTERNACIONAL DE POLÍTICAS PÚBLICAS, 9., 2019, São Luís. Anais[...]. São Luís: UFMA, 2019. Disponível em: http://www.joinpp.ufma.br/jornadas/joinpp2019/images/trabalhos/1012.pdf. Acesso em: 11 maio 2020.

BEZERRA, Josinete de Carvalho. Crise, fundo público e Programa Criança Feliz: sucateamento da Política de Assistência Social? In: JORNADA INTERNACIONAL DE POLÍTICAS PÚBLICAS, 9., 2019, São Luís. Anais[...].São Luís: UFMA, 2019. Disponível em: http://www.joinpp.ufma.br/jornadas/joinpp2019/images/trabalhos/trabalho_submissaold_903_9035cbb57c4b c623.pdf. Acesso em: 11 maio 2020.

BOTH, Lizandra Inês. Construção de espaços de participação e mobilização na Política de Assistência Social. In: JORNADA INTERNACIONAL DE POLÍTICAS PÚBLICAS, 9., 2019, São Luís. Anais[...].São Luís: UFMA, 2019a. Disponível em:

http://www.joinpp.ufma.br/jornadas/joinpp2019/images/trabalhos/trabalho_submissaoid_74_745c58e59 3e74ac.pdf. Acesso em: 11 maio 2020. 
BOTH, Lizandra Inês. Política de Assistência Social: conquistas, resistências e mobilização. In: JORNADA INTERNACIONAL DE POLÍTICAS PÚBLICAS, 9., 2019, São Luís. Anais[...].São Luís: UFMA, 2019b. Disponível em:

http://www.joinpp.ufma.br/jornadas/joinpp2019/images/trabalhos/trabalho_submissaoid_74_745c58e54 72b5ff.pdf. Acesso em: 11 maio 2020.

BRAGA, Iracilda Alves. Trabalho social com familias no SUAS: requisições profissionais e especificidades metodológicas.In: ENCONTRO INTERNACIONAL E NACIONAL DE POLÍTICA SOCIAL, 1., 2018, Vitória. Anais[...].Vitória: UFES, 2018. p. 1-16. Disponível em: http://periodicos.ufes.br/einps/article/view/20020. Acesso em: 11 maio 2020.

BRASIL. Lei n 12.101, de 27 de novembro de 2009.Dispõe sobre a certificação das entidades beneficentes de Assistência Social; regula os procedimentos de isenção de contribuições para a Seguridade Social; altera a Lei $n^{0} 8.742$, de 7 de dezembro de 1993; revoga dispositivos das Leis $n^{0 \mathrm{~s}}$ 8.212, de 24 de julho de 1991, 9.429, de 26 de dezembro de 1996, 9.732, de 11 de dezembro de 1998, 10.684, de 30 de maio de 2003, e da Medida Provisória n 2.187-13, de 24 de agosto de 2001; e dá outras providências. Diário Oficial [da] República Federativa do Brasil, Poder Executivo, Brasília, DF, 28 nov. 2009a. Disponível em: http://www.planalto.gov.br/ccivil_03/_ato20072010/2009/lei/l12101.htm. Acesso em: 8 ago. 2020.

CARRARO, Gissele. Vigilância Socioassistencial: ferramenta acessível ao controle social e base empírica à educação permanente. In: SPOSATI, Aldaíza et al. Vigilância Socioassistencial e gestão da informação: pesquisa e planejamento. JORNADA INTERNACIONAL DE POLÍTICAS PÚBLICAS, 8., 2017, São Luís. Anais[...].São Luís: UFMA, 2017. p. 25-36. Disponível em: http://www.joinpp.ufma.br/jornadas/joinpp2017/pdfs/mesas/vigilanciasocioassistencialegestaodainforma caopesquisaeplanejamento.pdf. Acesso em: 11 maio 2020.

CARVALHO, Alba Maria Pinho de; BEZERRA, Leila Maria Passos de Sousa. Percepções dos(as) sujeitos(as) da pesquisa sobre a Política de Assistência Social: os olhares de gestores(as), trabalhadores(as), conselheiros(as) e usuários(as). In: ENCONTRO INTERNACIONAL E NACIONAL DE POLÍTICA SOCIAL, 1., 2019, Vitória. Anais[...].Vitória: UFES, 2019. p. 1-15. Disponível em: http://periodicos.ufes.br/einps/article/view/25194. Acesso em: 11 maio 2020.

CARVALHO, Janaína Lucélia Oliveira de; SILVA, Maria do Rosário de Fátima e. Participação e controle social: refletindo sobre a atuação dos usuários na implementação do SUAS na gestão municipal. In: JORNADA INTERNACIONAL DE POLÍTICAS PÚBLICAS, 8., 2017, São Luís. Anais[...].São Luís: UFMA, 2017. Disponível em:

https://mail.google.com/mail/u/0/\#search/joinpp.ufma\%40gmail.com/fmfcgxwhndbkmxjgcrjtvgnhjpxmtpm q?projector=1\&messagepartid=0.2. Acesso em: 11 maio 2020.

CASTRO, leda Maria Nobre de. Cultura política e Assistência Social: entre velhos/novos conceitos, a encruzilhada do SUAS. In: JORNADA INTERNACIONAL DE POLÍTICAS PÚBLICAS, 8., 2017, São Luís. Anais[...].São Luís: UFMA, 2017. Disponível em:

http://www.joinpp.ufma.br/jornadas/joinpp2017/pdfs/eixo14/culturapoliticaeassistenciasocialentrevelhos novosconceitosaencruzilhadadosuas.pdf. Acesso em: 11 maio 2020. 
DAGNINO, Evelina. Construção democrática, neoliberalismo e participação: os dilemas da confluência perversa. Revista Política \& Sociedade, Florianópolis, n. 5, p. 139-164, 2004. Disponível em: https://periodicos.ufsc.br/index.php/politica/article/view/1983/1732. Acesso em: 23 set. 2019.

DAGNINO, Evelina; OLVERA, Alberto J.; PANFICHI, Aldo. Para uma outra leitura da disputa democrática na América Latina. In: DAGNINO, Evelina; OLVERA, Alberto J.; PANFICHI, Aldo (org.). A disputa pela construção democrática na América Latina. São Paulo: Paz e Terra; Campinas: Unicamp, 2006. p. 13-91.

ERCOLE, Flávia Falci; MELO, Laís Samara de; ALCOFORADO, Carla Lúcia Goulart Constant. Revisão Integrativa versus Revisão Sistemática. Revista Mineira de Enfermagem, Belo Horizonte, v. 18, n. 1, p. 9-12, 2014. Disponível em: https://www.reme.org.br/artigo/detalhes/904. Acesso em: 11 maio 2020.

FARIAS, Mara Regina A. da Costa; COELHO, Maria Ivonete Soares. Gênero, autonomia e políticas de enfrentamento à pobreza no Brasil: reflexões sobre o Programa Bolsa Família. In: JORNADA INTERNACIONAL DE POLÍTICAS PÚBLICAS, 8., 2017, São Luís. Anais[...].São Luís: UFMA, 2017. Disponivel em:

http://www.joinpp.ufma.br/jornadas/joinpp2017/pdfs/eixo6/generoautonomiaepoliticasdeenfrentamentoa pobrezanobrasilreflexoessobreobolsafamilia.pdf. Acesso em: 11 maio 2020.

HARVEY, David. A condição pós-moderna. São Paulo: Loyola, 1992.

LIMA, Lidiane Ramos. Mulheres e poder: participação política em tempo de desmontes sociais. In: JORNADA INTERNACIONAL DE POLÍTICAS PÚBLICAS, 8., 2017, São Luís. Anais[...].São Luís: UFMA, 2017. Disponível em:

http://www.joinpp.ufma.br/jornadas/joinpp2017/pdfs/eixo7/mulheresepoderparticipacaopoliticaemtempo dedesmontessociais.pdf. Acesso em: 11 maio 2020.

MACHADO, Suelen Borges. A avaliação dos serviços da proteção social básica da Assistência Social: uma análise de município de médio porte da região metropolitana do estado do Rio de Janeiro. In: JORNADA INTERNACIONAL DE POLÍTICAS PÚBLICAS, 8., 2017, São Luís. Anais[...].São Luís: UFMA, 2017. Disponível em:

http://www.joinpp.ufma.br/jornadas/joinpp2017/pdfs/eixo3/aavaliacaodosservicosdaprotecaosocialbasic adaassistenciasocialumaanalisedemunicipiod.pdf. Acesso em: 11 maio 2020.

MOTA, Ana Elizabete. Cultura da crise e Seguridade Social: um estudo sobre as tendências da Previdência e da Assistência Social brasileira nos anos 80 e 90. São Paulo: Cortez, 1995.

NEVES, Sueiny Larissa de Sousa; OLIVEIRA, Karla Vianna Azevedo de. Caça às bruxas: a atual ofensiva neoliberal à filantropia no Brasil. In: SIMPÓSIO INTERNACIONAL ESTADO, SOCIEDADE E POLÍTICAS PÚBLICAS, 2., 2018, Teresina. Anais[...].Teresina: UFPI, 2018. p. 194-203. Disponível em: https://drive.google.com/file/d/1mjxqhn4cmevh3oz3wzzfmsi7rrreoek8/view. Acesso em: 11 maio 2020.

PARREIRA, Janaína Aparecida; BARCELOS, Fernanda Michele. Política de Assistência Social: avanços e retrocessos. In: JORNADA INTERNACIONAL DE POLÍTICAS PÚBLICAS, 8., 2017, São Luís. Anais[...].São Luís: UFMA, 2017. Disponível em:

http://www.joinpp.ufma.br/jornadas/joinpp2017/pdfs/eixo14/politicadeassistenciasocialavancoseretroces sos.pdf. Acesso em: 11 maio 2020. 
PLATAFORMA Sucupira. Cursos avaliados e reconhecidos. Área de avaliação. Área de conhecimento. Instituição de ensino. Disponível em:

https://sucupira.capes.gov.br/sucupira/public/consultas/coleta/programa/quantitativos/quantitativoles.jsf ?areaavaliacao=32\&areaconhecimento $=61000000$. Acesso em: 12 jun. 2020.

SILVA, Fátima Eugênia de Araújo et al. Vigilância socioassistencial e o controle social: a gestão do Cadastro Nacional de Entidades de Assistência Social - CNEAS. In: JORNADA INTERNACIONAL DE POLÍTICAS PÚBLICAS, 8., 2017, São Luís. Anais[...].São Luís: UFMA, 2017. Disponível em: http://www.joinpp.ufma.br/jornadas/joinpp2017/pdfs/eixo8/vigilanciasocioassistencialeocontrolesocialag estaodocadastronacionaldeentidadesdeassistenciasocialcneas.pdf. Acesso em: 11 maio 2020.

SILVA, Robson Roberto da. As relações entre Estado e sociedade civil no âmbito da PNAS/SUAS. In: JORNADA INTERNACIONAL DE POLÍTICAS PÚBLICAS, 8., 2017, São Luís. Anais[...].São Luís: UFMA, 2017. Disponível em:

http://www.joinpp.ufma.br/jornadas/joinpp2017/pdfs/eixo14/asrelacoesentreestadoesociedadecivilnoam bitodapnassuas.pdf. Acesso em: 11 maio 2020.

SINESPP. Apresentação. Disponível em: https://sinespp.ufpi.br/index.php. Acesso em: 12 jun. 2020.

VASCONCELOS, Maria das Graças de Oliveira. Impasses históricos da Política da Assistência Social: algumas retóricas falaciosas utilizadas em sua prática. In: JORNADA INTERNACIONAL DE POLÍTICAS PÚBLICAS, 8., 2017, São Luís. Anais [...].São Luís: UFMA, 2017. Disponível em: http://www.joinpp.ufma.br/jornadas/joinpp2017/pdfs/eixo14/impasseshistoricosdapoliticadaassistenciaso cialalgumasretoricasfalaciosasutilizadasemsuapratica.pdf. Acesso em: 11 maio 2020.

\section{Notas}

1 Os projetos político-ideológicos são compreendidos como projetos coletivos que orientam a ação política dos sujeitos a partir da articulação de concepções de mundo, de representações da vida em sociedade e de um conjunto de crenças, valores, princípios e interesses (DAGNINO, 2004; DAGNINO; OLVERA; PANFICHI, 2006).

2 Aldaíza de Oliveira Sposati, Maria Ozanira Silva e Silva, Maria Carmelita Yazbek, Raquel Raichelis, Berenice Rojas Couto, dentre outras.

3 Informações disponíveis no site dos Anais do evento, a saber: http://periodicos.ufes.br/einps/about. Acesso em: 12 jun. 2020.

4 Informações disponíveis no site do evento, a saber: https://sinespp.ufpi.br/index.php. Acesso em: 12 jun. 2020.

5 Dados colhidos na Plataforma Sucupira a partir das informações sobre os cursos avaliados e reconhecidos pela CAPES. Disponivel em: https://sucupira.capes.gov.br/sucupira/

public/consultas/coleta/programa/quantitativos/quantitativoies.jsf?areaavaliacao=32\&areaconhecimento $=61000000$. Acesso em: 12 jun. 2020.

${ }^{6}$ Corroboram-se as análises que compreendem o impeachmentda presidenta Dilma Rousseff como golpe defrações da classe dominante para assumir o poder e alcançar a efetivação de seus interesses.

7 Categoria utilizada por Dagnino (2004) para evidenciar o processo de ocultação das diferenciações entre os projetos políticos que disputavam o processo democrático nos anos 1990 e início dos anos 2000 no Brasil.

iTrabalho realizado com apoio da CAPES, Brasil. Código de Financiamento 001. 